\title{
The development and general morphology of the telencephalon of actinopterygian fishes: synopsis, documentation and commentary
}

\author{
Rudolf Nieuwenhuys
}

Received: 27 August 2010/Accepted: 2 October 2010/Published online: 26 October 2010

(C) The Author(s) 2010. This article is published with open access at Springerlink.com

\begin{abstract}
The Actinopterygii or ray-finned fishes comprise, in addition to the large superorder of teleosts, four other superorders, namely the cladistians, the chondrosteans, the ginglymodes, and the halecomorphs, each with a limited number of species. The telencephalon of actinopterygian fishes differs from that in all other vertebrates in that it consists of a pair of solid lobes. Lateral ventricles surrounded by nervous tissue are entirely lacking. At the end of the nineteenth century, the theory was advanced that the unusual configuration of the forebrain in actinopterygians results from an outward bending or eversion of its lateral walls. This theory was accepted by some authors, rejected or neglected by others, and modified by some other authors. The present paper is based on the data derived from the literature, complemented by new observations on a large collection of histological material comprising specimens of all five actinopterygian superorders. The paper consists of three parts. In the first, a survey of the development of the telencephalon in actinopterygian fishes is presented. The data collected show clearly that an outward bending or eversion of the pallial parts of the solid hemispheres is the principal morphogenetic event in all five actinopterygian superorders. In all of these superorders, except for the cladistians, eversion is coupled with a marked thickening of the pallial walls. In the second part, some aspects of the general morphology of the telencephalon in mature actinopterygians are highlighted. It is
\end{abstract}

R. Nieuwenhuys

The Netherlands Institute for Neuroscience, Meibergdreef 47,

1105 BA Amsterdam, The Netherlands

R. Nieuwenhuys $(\square)$

Papehof 25, 1391 BD Abcoude, The Netherlands

e-mail: RudolfN@planet.nl pointed out that (1) the degree of eversion varies considerably among the various actinopterygian groups; (2) eversion leads to the transformation of the telencephalic roof plate into a wide membrane or tela choroidea, which is bilaterally attached to the lateral or ventrolateral aspect of the solid hemispheres; (3) the lines of attachment or taeniae of the tela choroidea form the most important landmarks in the telencephalon of actinopterygians, indicating the sites where the greatly enlarged ventricular surface of the hemispheres ends and its reduced meningeal surface begins; (4) the meningeal surface of the telencephalon shows in most actinopterygians bilaterally a longitudinally oriented sulcus externus, the depth of which is generally positively correlated with the degree of eversion; (5) a distinct lateral olfactory tract, occupying a constant topological position close to the taenia, is present in all actinopterygians studied; and (6) this tract is not homologous to the tract of the same name in the evaginated and inverted forebrains of other groups of vertebrates. In the third and final section, the concept that the structural organization of the pallium in actinopterygians can be fully explained by a simple eversion of its walls, and the various theories, according to which the eversion is complicated by extensive shifts of its constituent cell groups, are discussed and evaluated. It is concluded that there are no reasons to doubt that the pallium of actinopterygian fishes is the product of a simple and complete eversion.

Keywords Evagination - Eversion - Lateral olfactory tract $\cdot$ Membranous roof $\cdot$ Sulcus externus - Taenia

$\begin{array}{ll}\text { Abbreviations } & \\ \text { blv } & \text { Blood vessels } \\ \text { chonds } & \text { Chondrosteans } \\ \text { clad } & \text { Cladistians }\end{array}$




$\begin{array}{ll}\text { D } & \text { Area dorsalis telencephali } \\ \text { Dd } & \text { Dorsal part of area dorsalis } \\ \text { D1 } & \text { Lateral part of area dorsalis } \\ \text { Dla, Dlb, Dlc } & \text { Subdivisions of lateral part of area dorsalis } \\ \text { Dm } & \text { Medial part of area dorsalis } \\ \text { DP(a) } & \text { Dorsal pallium } \\ \text { Dp } & \text { Posterior part of area dorsalis } \\ \text { ep } & \text { Ependymal cells } \\ \text { ginglym } & \text { Ginglymodes } \\ \text { hip } & \text { Primordium hippocampi } \\ \text { LP(a) } & \text { Lateral pallium } \\ \text { lge } & \text { Lateral ganglionic eminence } \\ \text { lote } & \text { Lateral olfactory tract in everted } \\ & \text { ?tul? forebrains } \\ \text { loti } & \text { Lateral olfactory tract in inverted } \\ & \text { forebrains } \\ \text { lv } & \text { Lateral ventricle } \\ \text { MP(a) } & \text { Medial pallium } \\ \text { mge } & \text { Medial ganglionic eminence } \\ \text { mot } & \text { Medial olfactory tract } \\ \text { nt } & \text { Nucleus taeniae } \\ \text { P1 } & \text { First pallial area (in cladistians) } \\ \text { P1d } & \text { Dorsal portion of first pallial area } \\ & \text { (in cladistians) } \\ \text { P1v } & \text { Ventral portion of first pallial area } \\ & \text { (in cladistians) } \\ \text { P2 } & \text { Second pallial area (in cladistians) } \\ \text { P3 } & \text { Third pallial area (in cladistians) } \\ \text { p } & \text { Pallium } \\ \text { pctx } & \text { Pallial cortex } \\ \text { pm } & \text { Pallial matrix } \\ \text { pir } & \text { Nucleus piriformis } \\ \text { psb } & \text { Pallial-subpallial boundary } \\ \text { Sep } & \text { Septum } \\ \text { sp } & \text { Subpallium } \\ \text { Str } & \text { Striatum } \\ \text { tch } & \text { Tela choroidea } \\ \text { tel } & \text { Teleosts } \\ \text { VP(a) } & \text { Ventral pallium } \\ \text { Sv } & \end{array}$

Symbols

$\begin{array}{ll}* & \text { Sulcus externus } \\ \rightarrow \quad \text { Taenia } & \end{array}$

\section{Introduction}

The Actinopterygii or ray-finned fishes constitute by far the largest subclass of vertebrates, encompassing more than 30,000 living species. The great majority of these are members of the superorder Teleostei, but the actinopterygians also comprise four other superorders, namely the Cladistia (bichirs and reedfishes) with 11 species, the
Chondrostei (sturgeons and paddlefishes) with 25 species, the Ginglymodi or gars with 7 species, and the Halecomorphi or bowfins with a single species.

The telencephalon of actinopterygian fishes differs from that of other vertebrates in consisting of a pair of solid lobes. Lateral ventricles surrounded by nervous tissue are entirely lacking. At the end of the nineteenth century, Gage (1893) advanced the theory that the unusual configuration of the actinopterygian forebrain is due to the fact that its lateral walls fold outward during development, whereas in all other vertebrates an inward bending or inversion of the lateral telencephalic walls occurs. A few years later, Studnička (1896) also concluded that in actinopterygians the walls of the forebrain are recurved laterally. The conception of Gage and Studnička became known as the eversion theory. This theory has been accepted by numerous later students of the forebrain of actinopterygian fishes, among them Johnston (1911), Holmgren (1920), Kuhlenbeck (1929), Meader (1939), Nieuwenhuys (1962a, b, 1963, 2009a), Bannister (1973), and Butler (2000). However, some authors (Droogleever Fortuyn 1961; Crosby et al. 1966; Schnitzlein 1968) have ignored or denied the existence of an eversion process in the forebrain of actinopterygians, whereas some others (Sheldon 1912; Northcutt and Braford 1980; Northcutt and Davis 1983; Braford 1995, 2009; Northcutt 2001, 2006, 2008; Yamamoto et al. 2007) maintained that the eversion is complicated by an extensive shift or rearrangement of cell groups along the ventricular surface of the telencephalon. Wullimann and collaborators (Wullimann and Rink 2002; Wullimann and Mueller 2004; Mueller and Wullimann 2009; Wullimann 2009) have recently advanced the theory that in teleosts, within the dorsal or pallial part of the telencephalon, two different zones are present: a dorsal zone, which is clearly everted, and a ventral zone which grows out laterally and does not participate in the eversion process, hence the designation: 'partial pallial eversion model'.

The present paper consists of three parts. In the first, a synopsis of the development of the telencephalon in actinopterygian fishes will be presented. In the second part, some aspects of the configuration and the general morphology of the telencephalon in mature actinopterygians will be surveyed and documented with photomicrographs These two parts are based on data previously published by other authors and myself, complemented by new observations on a large collection of histological material, encompassing serial sections through the brains of species belonging to all five actinopterygian superorders. In the third and final part, the concept that the structural organization of the pallium in actinopterygian fishes can be fully explained by a simple eversion of its walls, and the various theories, according to which the eversion is complicated by extensive shifts or rearrangements of its constituent cell 
groups, as well as the so-called 'partial pallial eversion model', will be discussed and evaluated.

\section{Materials and techniques}

The material studied includes transverse serial sections through the forebrains of the following species, stained according to the techniques added in brackets: the cladistians Erpetoichthys calabaricus (Bodian) and Polypterus ornatipinnis (Bodian), the chondrosteans Scaphirhynchus platorynchus (Nissl, Bodian) and Polyodon spathula (haematoxylin and eosin), the ginglymode Lepisosteus osseus (Nissl, Bodian), the halecomorph Amia calva (Nissl, Bodian), and numerous teleosts, among which Salmo gairdneri (Nissl, Bodian), Danio rerio (Nissl), Anguilla anguilla (Bodian), Mormyrus cashive (Weigert-Pal-paracarmine), Arius spec. (Weigert-Pal-paracarmine) and Synbranchus marmoratus (Weigert-Pal-paracarmine). In addition, serial sections through the heads of a number of larvae of the teleost Gasterosteus aculeatus, stained with haematoxylin and eosin, were studied.

\section{Development}

This survey of the development of the telencephalon of actinopterygian fishes is based on published data on the following species: the cladistian Polypterus senegalus (Nieuwenhuys et al. 1969; Fig. 1a-d), the chondrosteans Acipenser ruthenus (Nieuwenhuys 1964; Fig. 1e-h) and Acipenser naccarii (Vázquez et al. 2002), the ginglymodes Lepisosteus spec. (Källén 1950; Fig. 1j, k), the halecomorph Amia calva (Nieuwenhuys 1962b; Fig. 1m-p), the teleosts Salmo irideus (Nieuwenhuys 1960; Fig. 1q, r), Lebistes reticulatus (Kirsche 1967; Fig. 1s) and Ictalurus nebulosus (Johnston 1911; Fig. 1t), and on an analysis of larval material of the teleost Gasterosteus aculeatus (Fig. 2).

In an early embryonic stage, the anlage of the telencephalon of actinopterygian fishes is tube-shaped, just as in all other vertebrates. The side walls or lateral plates of the tube are thickened; they consist of a pseudostratified epithelium, from which the nervous tissue of the telencephalon will develop. At the dorsal side, the lateral plates are connected by the telencephalic part of the roof plate or lamina supraneuroporica. The ventral connection of the lateral plates, which is known as the lamina terminalis, is usually somewhat thicker than the roof plate (Fig. 1a, e). During further development, cell nuclei become rare in the most superficial parts of the lateral plates, and gradually the three well-known embryonic layers, matrix, mantle, and marginal, become defined (Fig. 1e). During a considerable period of development, the compact matrix zone in the ventral part of the lateral plates remains much thicker than in the rapidly expanding dorsal region (Fig. $1 \mathrm{~b}, \mathrm{k}, \mathrm{n}$ ). This structural difference renders it possible to divide the lateral plates into an area dorsalis telencephali or pallium and an area ventralis telencephali or subpallium. In later developmental stages and when mature, these two principal regions can generally be readily distinguished on account of cytoarchitectural differences (Fig. 1d, h, l, p).

The morphogenesis of actinopterygian forebrains begins with a divergence of the lateral plates on the dorsal side, with consequent widening and thinning of the lamina supraneuroporica. These changes are accompanied or followed by an increase in thickness of the dorsal, pallial portions of the lateral plates, which start to bulge into the ventricular space. As a result of this uneven growth, the telencephalic ventricle, which is initially slit-like, now becomes T-shaped.

Later development is characterized by a further intraventricular expansion of the dorsal portions of the lateral plates. The taeniae, i.e. the lines of attachment of the lamina supraneuroporica, which have shifted laterally during an earlier phase, are displaced ventrally now. The lamina neuroporica itself is gradually transformed into a thin tela choroidea, which envelops the thickened dorsal portions of the forebrain. The expansion of the pallial portions of the lateral plates manifests itself initially mainly in the ventricular zone, but later the external zone becomes also involved. The meningeal surfaces of the lateral plates become curved and bilaterally a longitudinal groove, the sulcus externus, appears. Thus, the proceeding expansion of the pallial portions ultimately leads to a complete recurvature of the forebrain walls.

Whereas the protrusion of the pallial anlage into the ventricular space and the widening of the lamina supraneuroporica can be observed in all actinopterygians, during further development considerable differences between the various groups become manifest.

In cladistians, the initial eversion closely resembles that seen in other groups (compare Fig. 1b with Fig. 1k, o, q). Somewhat later, however, the morphologically most dorsal portions of the pallial anlagen show a relative thinning and recurve ventrolaterally, with consequent formation of bilateral external sulci (Fig. 1c). During further development the recurved portions of the pallial anlagen increase in size, and in a young adult stage the medial 'ascending' and lateral 'descending' portions of the pallium are separated by deep external sulci (Fig. 1d). Thus, in cladistians the recurvature occurs relatively very early, and this morphogenetic process is not accompanied by a thickening of the pallial walls, in contrast with all other actinopterygian groups.

In chondrosteans, the lateral plates diverge, but remain relatively thin for a long time. The telencephalic 
CLADISTIANS: Polypterus

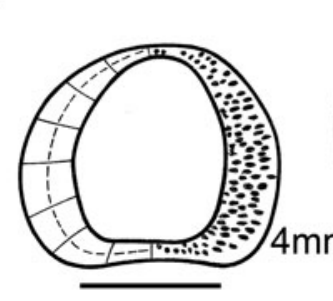

A

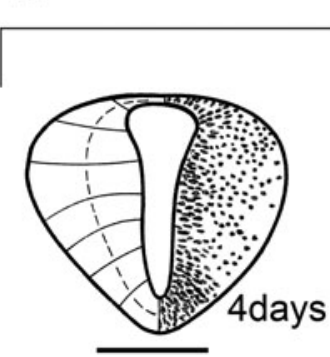

E

B
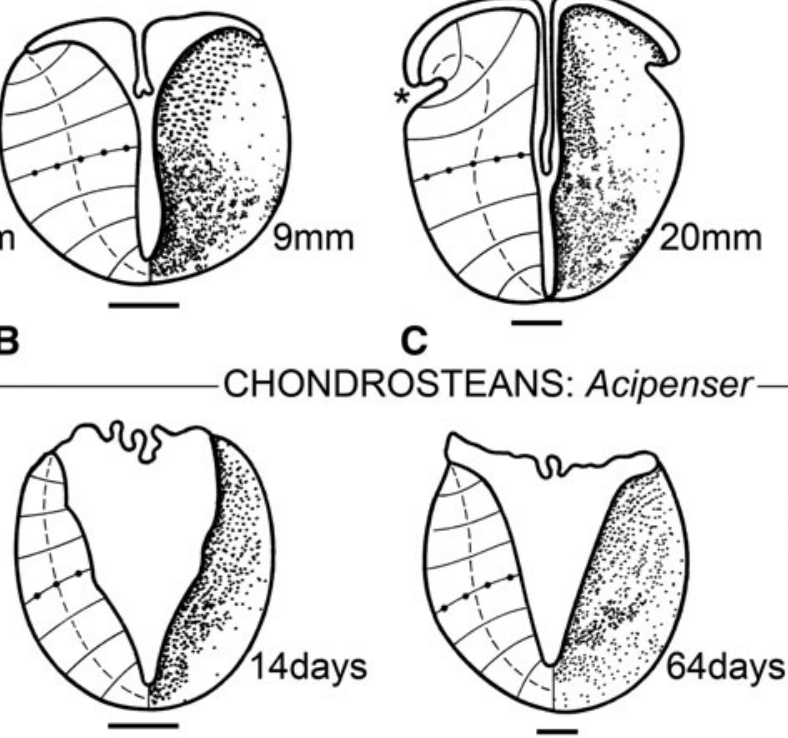

$\mathbf{F}$

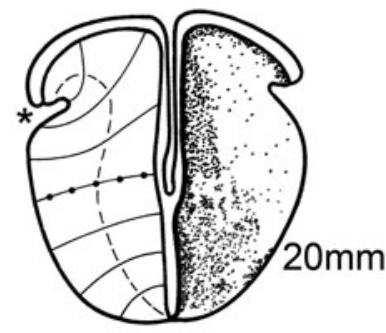

C

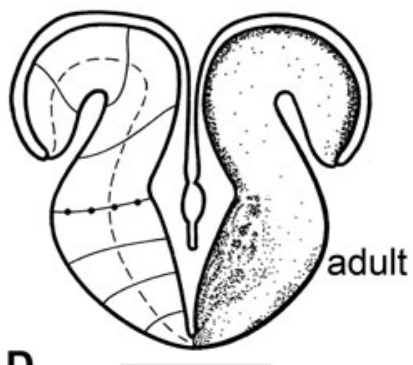

D

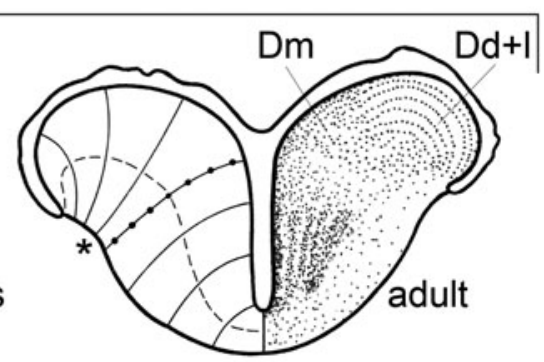

H

GINGLYMODES: Lepisosteus

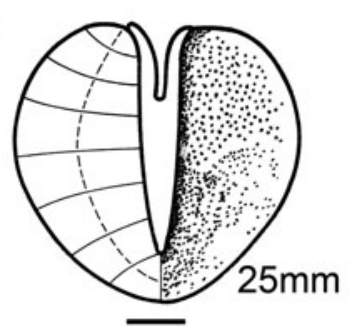

J

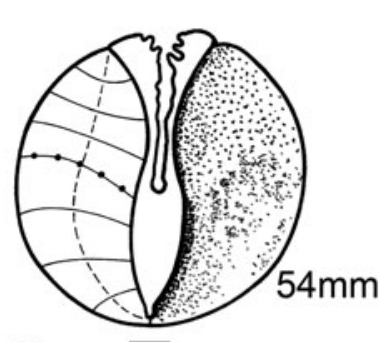

K HALECOMORPHS: Amia

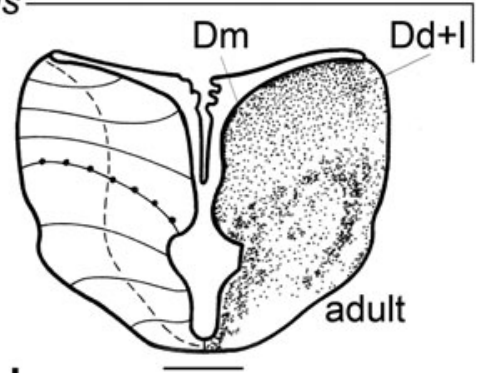

L
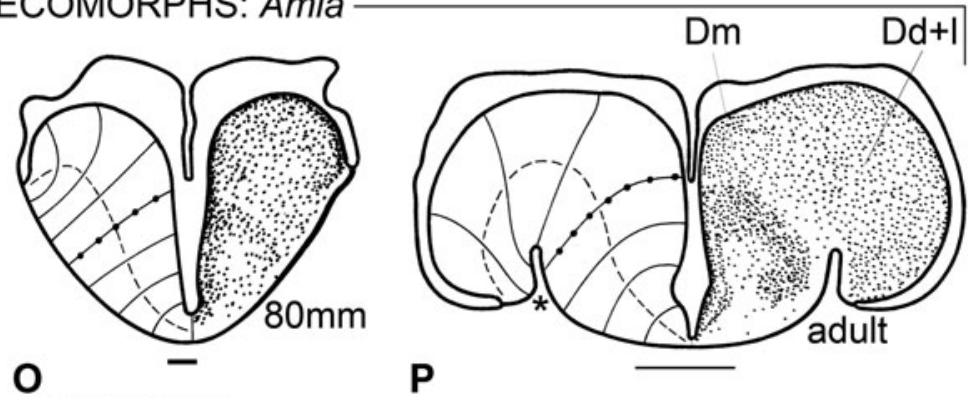

TELEOSTS -
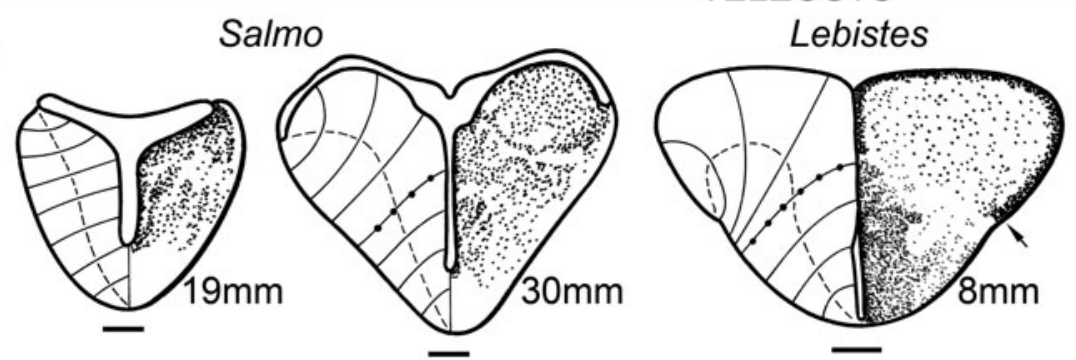

$\mathbf{Q}$

$\mathbf{R}$

$\mathbf{S}$

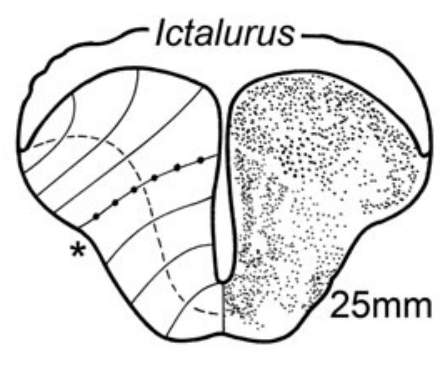

$\mathbf{T}$ 
4 Fig. 1 The development of the telencephalon in actinopterygian fishes. Transverse sections through the telencephalon of larval specimens of the cladistian Polypterus $(\mathbf{a}-\mathbf{c})$, the chondrostean Acipenser (e-g), the ginglymode Lepisosteus ( $\mathbf{j}, \mathbf{k})$, the halecomorph Amia (m-o) and the teleosts Salmo (q, r), Lebistes (s) and Ictalurus (t), and of adult specimens of Polypterus (d), Acipenser (h), Lepisosteus (1), and Amia (p). In all of the figures, the distribution of neuronal perikarya (or their precursors) is shown to the right, and the course of radial vectors, connecting the ventricular surface with the meningeal surface, is shown to the left. The vectors coinciding with the pallial-subpallial boundaries are marked with dots. The dashed curves, which interconnect the midpoints of the vectors, indicate the degree of eversion. The total length or the age (in posthatching days) of the larvae is indicated. Thick bar scales $100 \mu \mathrm{m}$; thin bar scales $1 \mathrm{~mm}$. The sources from which the figures are reproduced or derived are as follows: a-d Nieuwenhuys et al. (1969); e-h Nieuwenhuys (1964); j, k Källén (1950); I Northcutt and Braford (1980); m-p Nieuwenhuys (1962a); q, r Nieuwenhuys (1960); s Kirsche (1967); t Johnston (1911)

ventricular cavity is triangular rather than T-shaped during that period (Fig. 1f, g). In a later developmental phase, the thickening and intraventricular expansion of the pallium still occurs, and a slight recurvature leads to the formation of shallow external sulci (Fig. 1h). In the transverse section, through the telencephalon of a juvenile specimen of the shovelnose sturgeon Scaphirhynchus, shown in Fig. 5a, these sulci are still absent, but in more mature specimens of the same species they can be clearly discerned (cf. Northcutt and Braford 1980: Figs. 12-14).

Although the histological structure of the telencephalon in mature ginglymodes is strikingly similar to that in halecomorphs (Fig. 11, p), the morphogenesis of that brain part shows considerable differences in these two groups. In ginglymodes, the anlage of the telencephalon maintains an essentially tube-shaped configuration for a relatively very long time (Fig. 1j). In the forebrain of the 54-mm-long specimen, shown in Fig. 1k, the dorsal divergence of the lateral plates and the consequent widening of the lamina supraneuroporica are still very slight, and the same holds true for the intraventricular protrusion of the pallial primordia. In mature ginglymodes, the bulging of the pallial portions has considerably increased, and the taeniae are displaced laterally, but the meningeal surfaces of the hemispheres have remained convex, and external sulci are lacking (Fig. 11). In the halecomorph Amia, on the other hand, the intraventricular expansion of the pallial primordia starts early (Fig. 1n, o), and in the adult stage, the telencephalic walls are strongly recurved. There are deep external sulci and the ventrolaterally attached tela choroidea envelops most of the telencephalon (Fig. 1p).

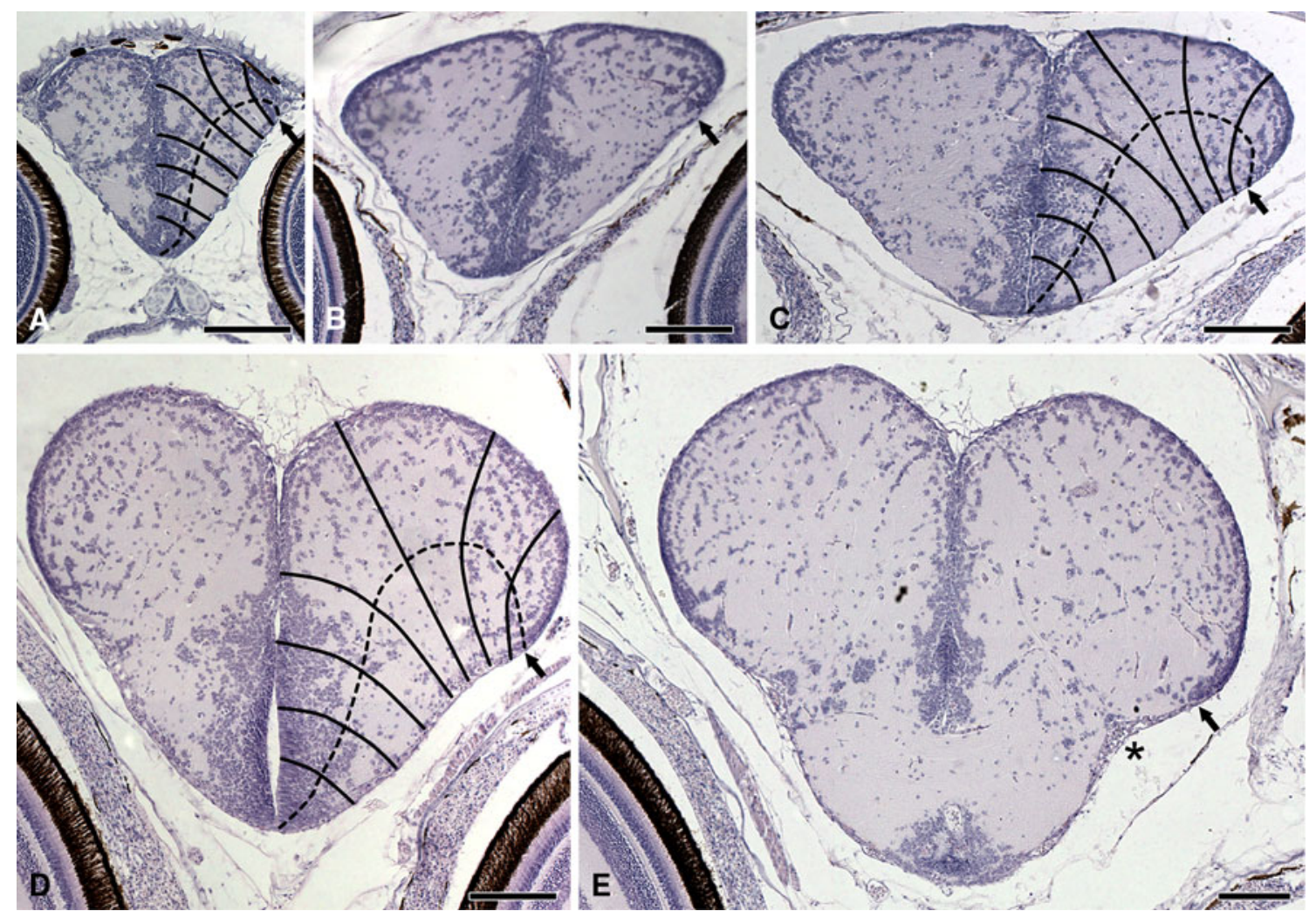

Fig. 2 Development of the telencephalon in a teleost. Transverse sections through the telencephalon of larvae of the three-spined stickleback Gasterosteus aculeatus, with a total length of $7 \mathrm{~mm}(\mathbf{a})$,
$12 \mathrm{~mm}$ (b), $16 \mathrm{~mm}(\mathbf{c}), 19 \mathrm{~mm}(\mathbf{d})$, and $22 \mathrm{~mm}(\mathbf{e})$. The sets of vectors and the dashed curves in $\mathbf{a}, \mathbf{c}$, and $\mathbf{d}$ give an impression of the progress of the eversion of the telencephalic walls. Bar scales $100 \mu \mathrm{m}$ 
In most teleosts, the morphogenesis of the telencephalon follows the pattern observed in the halecomorph Amia (Fig. $1 \mathrm{~m}-\mathrm{p}$ ). The intraventricular expansion of the pallial anlagen (Figs. 1s, 2a-c) is followed by a true recurvature of the telencephalic walls, leading to the appearance of external sulci (Figs. 1t, 2d, e). The amount of recurvature differs considerably among teleost species, and so does the depth of the external sulci (see next section).

The salmonids occupy a separate position within the teleosts because, just as in ginglymodes, in this group the intraventricular expansion of the pallial parts (Fig. 1q, r) is not followed by an outward bending of the telencephalic walls. Hence, the sulcus externus is lacking bilaterally, and the taeniae are located dorsolaterally (Figs. 1r, 4b, 5d).

A peculiarity, observed in our larval material of the teleost Gasterosteus, is that in this species the thin tela choroidea fuses at an early stage with the underlying ventricular surface of the pallial anlage (Fig. 2). Hence, the lateral extension of the telencephalic ventricle cannot be followed, and the location of the taeniae is hard to determine. In this species, the pallium shows throughout development a thin, very compact periventricular cellular zone. Interestingly, this zone retains in Gasterosteus, even in the adult stage, the proliferative capacity of a true matrix layer (Segaar 1965). Such a compact periventricular layer is also found in other actinopterygian species, including Polypterus (Fig. 1b-d), Lepisosteus (Fig. 1j-1), and Amia (Fig. 1n-p). In all of these species, the morphologically most dorsal end of this layer corresponds exactly with the location of the taenia. Hence, it may be assumed that this correspondence also exists in the developing telencephalon of Gasterosteus (Fig. 2, arrows) and in other teleost species in which the lateral parts of the telencephalic ventricular cavity have obliterated as for instance Lebistes (Fig. 1s, arrow).

In the survey presented above, I have confined myself mainly to external form changes. For an appraisal of the concomitant internal changes, it is of paramount importance that in all vertebrates, the central nervous system contains a built-in system of natural coordinates (Nieuwenhuys 1998a, b, 2009d). This natural coordinate system (NCS) includes (a) two natural planes, i.e. the ventricular and meningeal surfaces of the neural tube, (b) a set of radially oriented curves, which connect these two surfaces, and (c) a set of tangential curves, connecting the floor and roof plates. The radial curves or vectors manifest themselves in the direction and orientation of (1) the matrix cells, which during early development span the widths of the neural tube walls, (2) the radial glial cells, which are present during early neurogenesis in all vertebrates and throughout development in most anamniotes, and (3) the blood vessels, which enter the walls of the neural tube via the meningeal surface. The tangential component of the NCS manifests itself in the course of 'arcuate fibres', i.e. axonal processes which during early development pass dorsoventrally, directly peripheral to the matrix layer. Numerous additional arcuate fibres are generated during further development. It is important to note that the processes of the radial glia cells and the arcuate fibres form an important substrate for the radial and tangential migrations of neuroblasts as will be discussed in the final section of this paper.

Previous studies on the course of the blood vessels in the forebrain of larval and adult actinopterygians (Nieuwenhuys 1962b, 1964) and on the orientation of the telencephalic ependymal gliocytes (Nieuwenhuys 1962b; Kálmán 1998; Forlano et al. 2001), pictorially summarized in Fig. 3, justify the introduction of vectors as drawn in the sections shown in Figs. 1 and 2a, c, d. With the help of these vectors the morphogenetic phenomena of eversion and inversion can be defined, as follows: A part of the wall of the brain is everted if the line which interconnects the midpoints of the vectors shows a curve which is directed with its convex side towards the ventricle; in the opposite
Fig. 3 Semidiagrammatic transverse sections through a moderately everted (a) and a more strongly everted actinopterygian telencephalon (b). Note the differences in (1) the extension of the telae choroideae, (2) the location of the taeniae, (3) the overall patterns of the blood vessels and (4) of the ependymal gliocytes, (5) the topographical position of the lateral olfactory tracts, and (6) the absence in $\mathbf{a}$, but presence in $\mathbf{b}$ of a sulcus externus
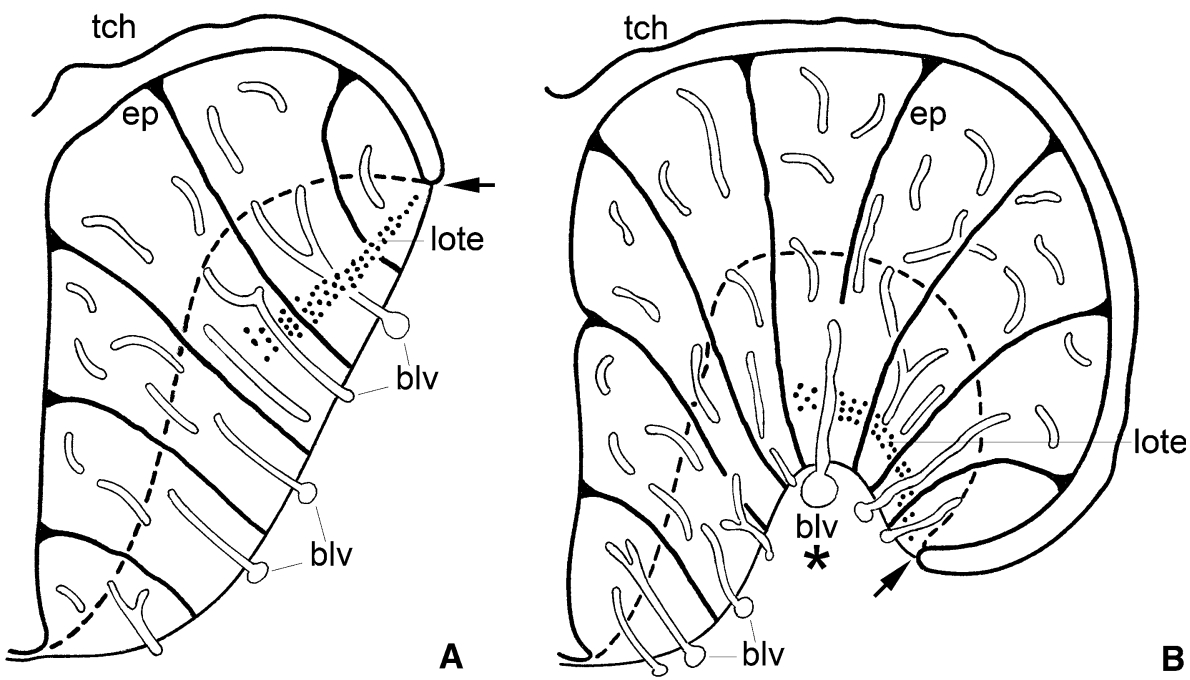
case, we call the brain wall inverted (Nieuwenhuys 1962b; 2009a). If this definition is accepted, it may be concluded that in all actinopterygian groups the walls of the telencephalon evert during ontogenesis, and that this eversion is confined to the dorsal, pallial parts of the hemispheres (Figs. 1, 2). It should be emphasized that the eversion occurs not only laterally but also caudally. This appears from the facts that a large part of the caudal surface of the actinopterygian telencephalic lobes is covered with ependyma, and that the caudal parts of the taeniae arch medially (cf. Northcutt 2006: Fig. 1).

The findings reported above fully confirm the correctness of the eversion theory as enunciated by Gage (1893) and Studnička (1896). It follows that interpretations of the actinopterygian forebrain, in which the eversion of the pallium is neglected or denied, such as those of Droogleever Fortuyn (1961), Crosby et al. (1966), and Schnitzlein (1968), can be put aside as incorrect.

\section{The general morphology of the telencephalon}

In this section, some features of the general morphology of the telencephalon in mature actinopterygians will be summarized in a number of statements, printed in italics. Each of these statements will be followed by a brief comment and will be accompanied by pictorial documentation.

1. The degree of eversion of the telencephalic walls varies considerably among the various groups of actinopterygians (Johnston 1911; Nieuwenhuys 1963; Northcutt and Braford 1980)
It has already been mentioned that in cladistians eversion is very pronounced, but is not accompanied by thickening of the pallial walls (Fig. 1d). In chondrosteans (Figs. 1h, 4b, 5a), ginglymodes (Fig. 11) and salmonid teleosts (Figs. 4b, $5 \mathrm{~d}$ ), the eversion is only slight, but in the halecomorph Amia (Fig. 5c) and in most teleost groups (Fig. 4c-h) it is more advanced. In all actinopterygians, the ependymal or ventricular surface of the solid telencephalic lobes exceeds the meningeal surface in size, and this discrepancy is positively correlated with the degree of eversion (Figs. 3, 4). In some groups of teleosts with strongly everted hemispheres, most notably in the osteoglossomorphs, the pallium is subdivisible into five sharply delineated regions, some of which protrude as separate lobes into the ventricular cavity (Fig. 6a). These various regions show considerable differences in histological structure and fibre connections (Herrick 1891; Nieuwenhuys 1962a). It is quite remarkable that in mammals, as well as in some teleosts, the area situated directly adjacent to the greatly enlarged external surface of the pallium is occupied by a zone of highly differentiated grey matter although this striking similarity is underlain by an extreme difference. Whereas in the evaginated forebrain of mammals, the pallial zone of highly differentiated grey, i.e. the cerebral cortex, occupies a submeningeal position (Fig. 6b), in the everted forebrain of teleosts, this zone borders directly on the ventricular surface (Fig. 6a).

2. Eversion of the telencephalic walls leads to transformation of the telencephalic roof plate into a wide, thin ependymal membrane, the tela choroidea.

This membranous roof is conspicuously present and entirely intact in all of the material of non-teleost

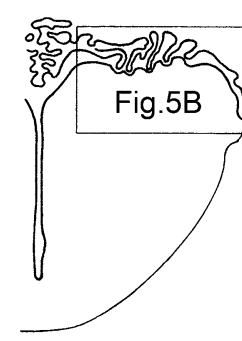

A

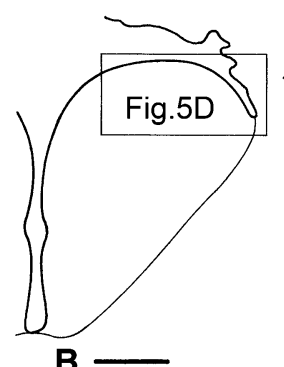

B -
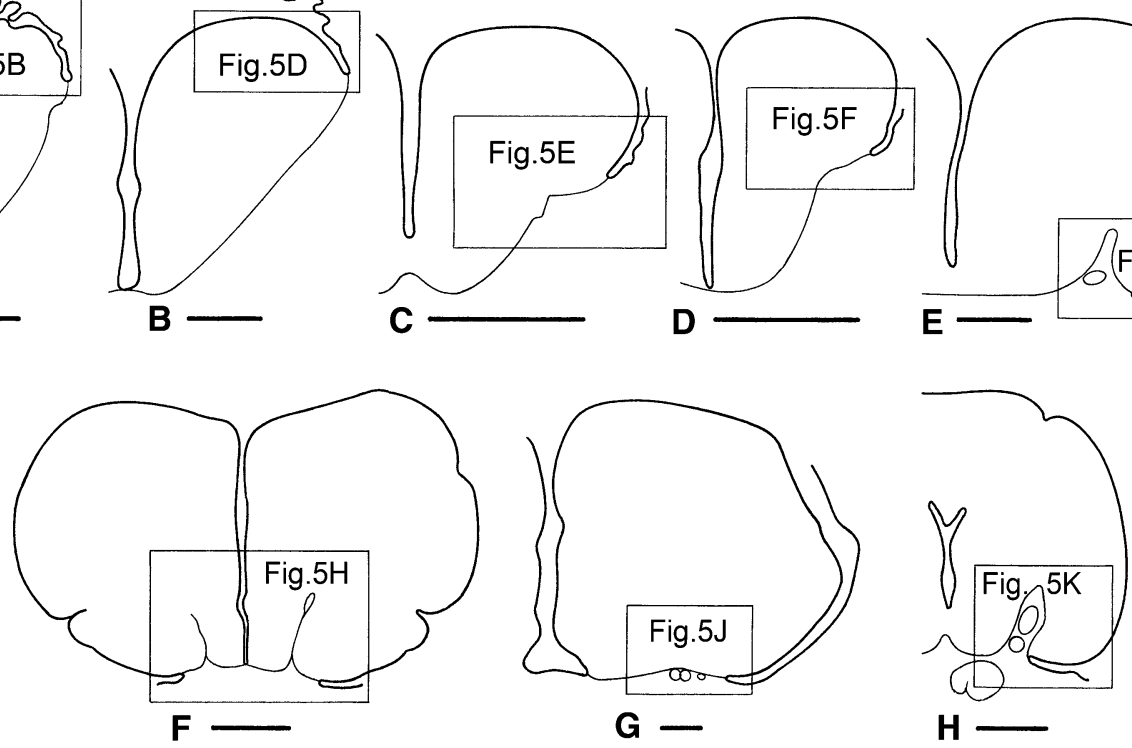

Arius spec. (g), and Synbranchus marmoratus (h) to show the location of the photomicrographs presented in Fig. 5. Bar scales $500 \mu \mathrm{m}$
Fig. 4 Outlines of transverse sections through the telencephalon of the chondrostean Polyodon spathula (a), the teleosts Salmo gairdneri (b), Danio rerio (c, d), Anguilla anguilla (e), Mormyrus cashive (f), 

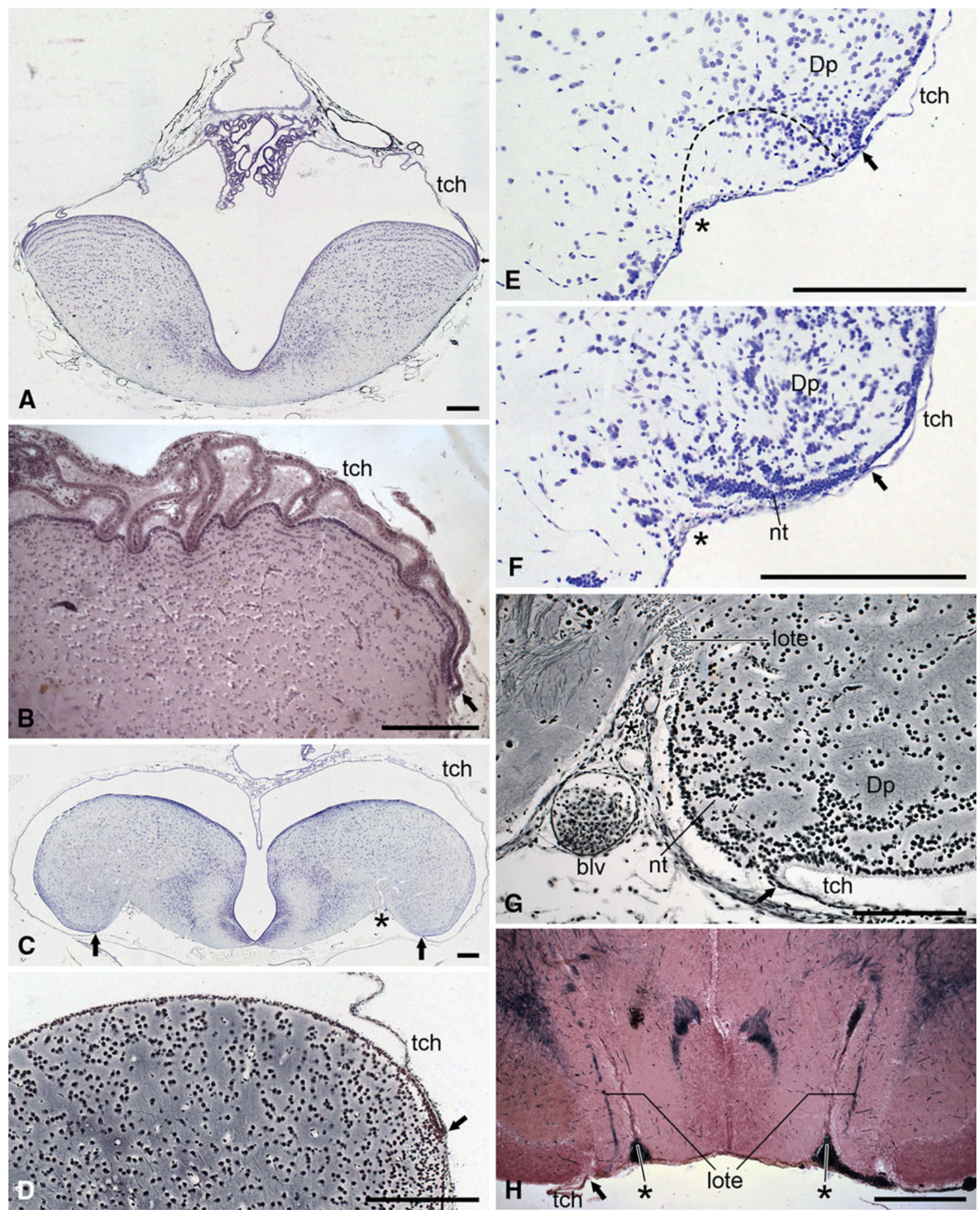

Fig. 5 Photomicrographs of transverse sections through the telencephalon of actinopterygian fishes to show some general features of this brainpart, including the location of the attachment of the tela choroidea (i.e. the taenia), the depth of the sulcus externus, and the position of the lateral olfactory tract. a The shovelnose sturgeon Scaphirhynchus platorynchus; b the paddlefish Polyodon spathula; c the bowfin Amia calva; d the trout Salmo gairdneri; e, f the

zebrafish Danio rerio; $\mathbf{g}$ the eel Anguilla anguilla; $\mathbf{h}$ the elephant fish Mormyrus cashive; $\mathbf{j}$ the marine catfish Arius spec.; $\mathbf{k}$ the swamp eel Synbranchus marmoratus. The staining techniques used are as follows: a, c, e, f Nissl; b haematoxylin and eosin; d, g Bodian; $\mathbf{h}-\mathbf{k}$ Weigert-Pal-paracarmine. The dotted line in $\mathbf{e}$ indicates the delineation of cell mass Dp as presented by Mueller and Wullimann (2009) in their Fig. 4c. Bar scales $250 \mu \mathrm{m}$ 

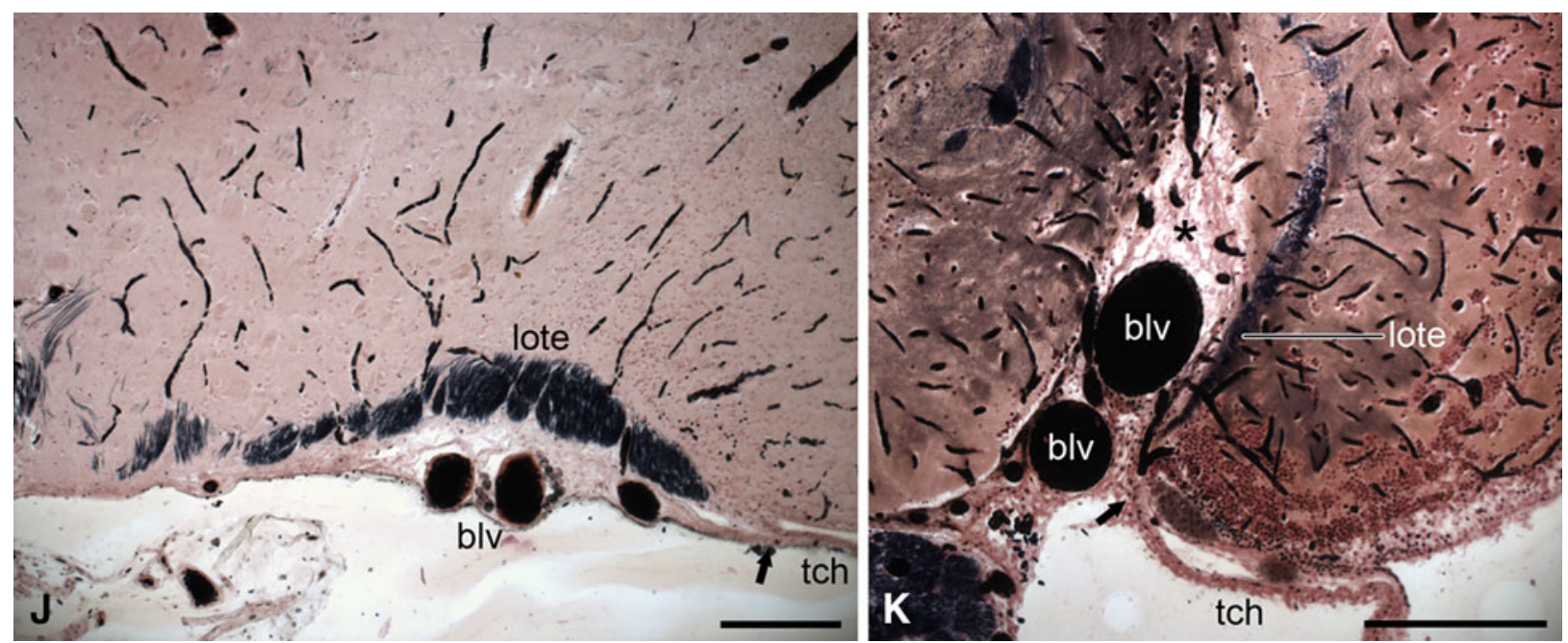

Fig. 5 continued

actinopterygians studied (Figs. 1d, 5a-c). In the paddlefish Polyodon, it is strongly folded, and most remarkably, the folds correspond to the small depressions in the ependymal surface of the pallium (Fig. 5b). The membranous roof is incomplete in the histological material of almost all of the approximately 40 teleost-species studied, although in many of them its morphologically most lateral parts are preserved (Figs. $4 \mathrm{~b}-\mathrm{h}, 5 \mathrm{~d}-\mathrm{k}$ ), indicating the fragility of this structure and its vulnerability to preparative damage.

3. The taeniae, i.e. the lines of attachment of the membranous roof, are highly important morphological

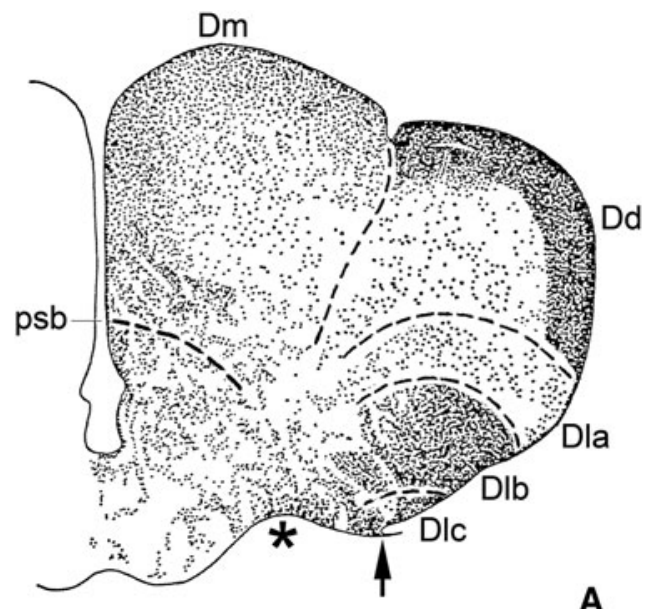

A

Fig. 6 Two different modes of formation of an extensive and highly differentiated zone of superficially situated pallial grey. a Transverse section through the telencephalon of the osteoglossiform teleost Scleropagus formosus. The greatly extended ependymal surface of the everted pallium is bordered by five, sharply defined, radially oriented cytoarchitectonic areas: Dm, Dd, Dla, Dlb, and Dlc. During ontogeny, the constituent cells of these areas have migrated inward from their respective ventricular matrix zones. b Diagrammatic transverse landmarks in the telencephalon of actinopterygian fishes. They mark the morphologically most dorsal points of the walls of the hemispheres and the sites where the enlarged ventricular surface of these walls end and their reduced meningeal surface begin. Moreover, the location of the taeniae is a direct indicator of the degree of eversion.

It is to be regretted that in many recent publications on the telencephalon of actinopterygians, the membranous roof, the location of the taeniae and the distinction between the ventricular surface and the meningeal surface of the solid hemispheres are completely neglected. Due to these

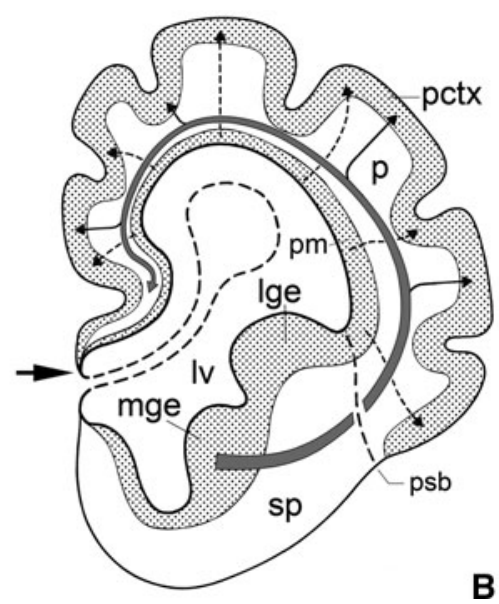

section through the telencephalon of a hypothetical mammalian foetus. The meningeal pallial surface is enlarged by folding. Interrupted arrows indicate that neuroblasts, originating from the ventricular pallial matrix, migrate radially outward to form the pallial cortex. The large curved arrow and its branches indicate that neuroblasts, stemming from the medial ganglionic eminence, migrate tangentially towards the pallium, where they contribute to the formation of the pallial cortex 
omissions, an adequate morphological interpretation of the cell masses contained within the forebrains described in these papers is highly compromised, and this holds in particular for those located in the morphologically most dorsal parts of the hemispheres (see Nieuwenhuys 2009a, b for discussion of this problem).

The taeniae are sites where the ependymal lining of the solid telencephalic lobes is continuous with the ependymal layer of the membranous roof as observed in the actinopterygian series described in this paper (Fig. 5a-k). In some teleosts, this ependymal layer consists of thin, flattened cells from its first appearing, a feature that may hamper the localization of the taenia. The zebrafish, Danio rerio is a remarkable case in point. This species, which is easy to breed, is currently used in a variety of neurogenetic studies, and is therefore proclaimed to be a model species (Ampatzis and Dermon 2010; Friedrich et al. 2010; Kastenhuber et al. 2010; Mueller et al. 2004; Wullimann and Mueller 2004). However, in none of the zebrafish studies that have yet come to my attention, the location of the taeniae has been established. This implies that the extent of the telencephalic ventricular and meningeal surfaces in this fish is unknown, and this lack of a salient piece of information has led to the interpretational problems discussed in the final section of this paper. Fortunately, the taeniae were clearly visible in our series of the zebrafish (Fig. 5e, f).

4. The meningeal surface of the telencephalon shows in many actinopterygians bilaterally a longitudinal groove, the sulcus externus. The depth of this sulcus is generally positively correlated with the degree of eversion.

The sulcus externus is absent in the slightly everted forebrains of the juvenile specimen of the chondrostean Scaphirhynchus shown in Fig. 5a, as well as in the chondrostean Polyodon (Figs. 4a, 5b), the ginglymode Lepisosteus (Fig. 11) and salmonid teleosts (Figs. 4b, 5d); it is only shallow in the moderately everted forebrain of the zebrafish (Figs. 4c, d, 5e, f), but it is well marked in the halecomorph Amia (Fig. 5c) and in most teleosts. In the strongly everted forebrains of the teleosts Anguilla and Synbranchus, the sulcus externus presents itself as a deep incisure, filled with blood vessels (Fig. $5 \mathrm{~g}$, k). Butler (2000) observed similar relations in the teleost Astronotus. In the, likewise strongly everted telencephalon of the teleost Mormyrus, the sulcus externus is reduced to a deep, narrow slit (Fig. 4h). The forebrain of the teleost Arius forms an exception to the rule: 'the more pronounced the eversion, the deeper the sulcus externus', since in that genus eversion is advanced, but the sulcus externus is poorly developed (Figs. $4 \mathrm{~g}, 5 \mathrm{j}$ ).

5. A distinct lateral olfactory tract, occupying a constant topological position, appears to be present in all actinopterygian species studied (Nieuwenhuys 1963, 2009a). This
Fig. 7 The cell masses in the pallium of actinopterygian fishes. Transverse sections through the telencephalon of the urodele amphibian Ambystoma tigrinum (a), and the cladistian Polypterus ornatipinnis (b), and through the rostral $(\mathbf{c}, \mathbf{e})$ and caudal parts (d, f) of the telencephalon of the teleosts Gasterosteus aculeatus (c, d) and Danio rerio $(\mathbf{e}, \mathbf{f})$. In $\mathbf{a}-\mathbf{f}$, the course of radial vectors and the boundaries of the principal cell masses are shown to the left; the cytoarchitectonic organization and the course of the olfactory tracts passing to the pallium are shown to the right. The open arrows in $\mathbf{a}$ and $\mathbf{e}$ indicate streams of cells, which migrate tangentially from the subpallium to the pallium. g-k Summary diagrams showing hypothetical shifts of cell masses in the pallium of actinopterygian fishes, according to Sheldon (1912) (g), Northcutt and Braford (1980) (h), and Yamamoto et al. (2007) (j, k). For explanation, see text

tract is not homologous with the lateral olfactory tract in the evaginated and inverted telencephala of other groups of vertebrates.

The lateral olfactory tract consists in actinopterygians of a thin sheet of myelinated fibres. Proceeding caudally from the olfactory bulb, it arches over the sulcus externus (where present) to fan out in the caudal portions of the area dorsalis or pallium. In teleosts, it terminates specifically in a distinct cell mass, known as the posterior part of the area dorsalis (Dp). The most lateral part of the lateral olfactory tract is, throughout its rostrocaudal course, invariably situated close to the taenia (Figs. 3, 5h-k). This constant relationship between the lateral olfactory tract and the taenia is of great practical interest because it renders it possible to determine the position of the taenia in histological sections in which this landmark is not otherwise visible. It is important to note that a lateral olfactory tract has been identified in all groups of gnathostomes with evaginated and inverted telencephala. In all of these groups, this tract is far removed from the taenia and terminates in a region that is likewise distant from that landmark (Fig. 7a). Because of their entirely different topological positions, I consider the lateral olfactory tract in everted forebrains (indicated by the acronym lote) as not homologous with the same-named tract in inverted forebrains (loti) (Nieuwenhuys 2009a).

\section{Simple or modified eversion?}

In this section, I will discuss current ideas concerning actinopterygian forebrain eversion, including the concept that the structural organization of the pallium in actinopterygian fishes can be fully explained by a simple eversion of its walls, followed by the various theories, proposing that eversion is complicated by extensive shifts of one or more of its constituent cell groups. This discussion will be prefaced by some remarks on the organization of the pallium in tetrapods. 

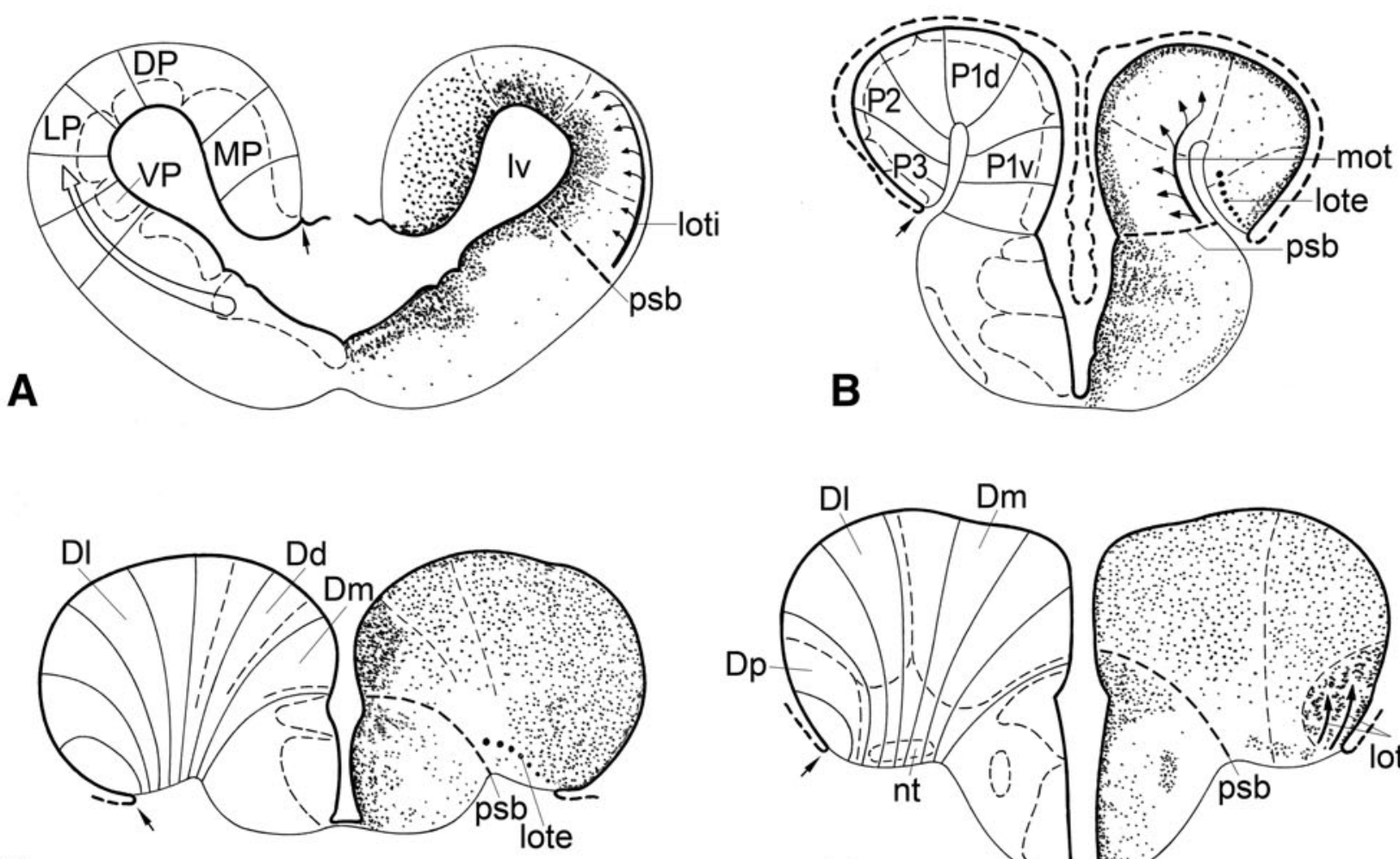

C
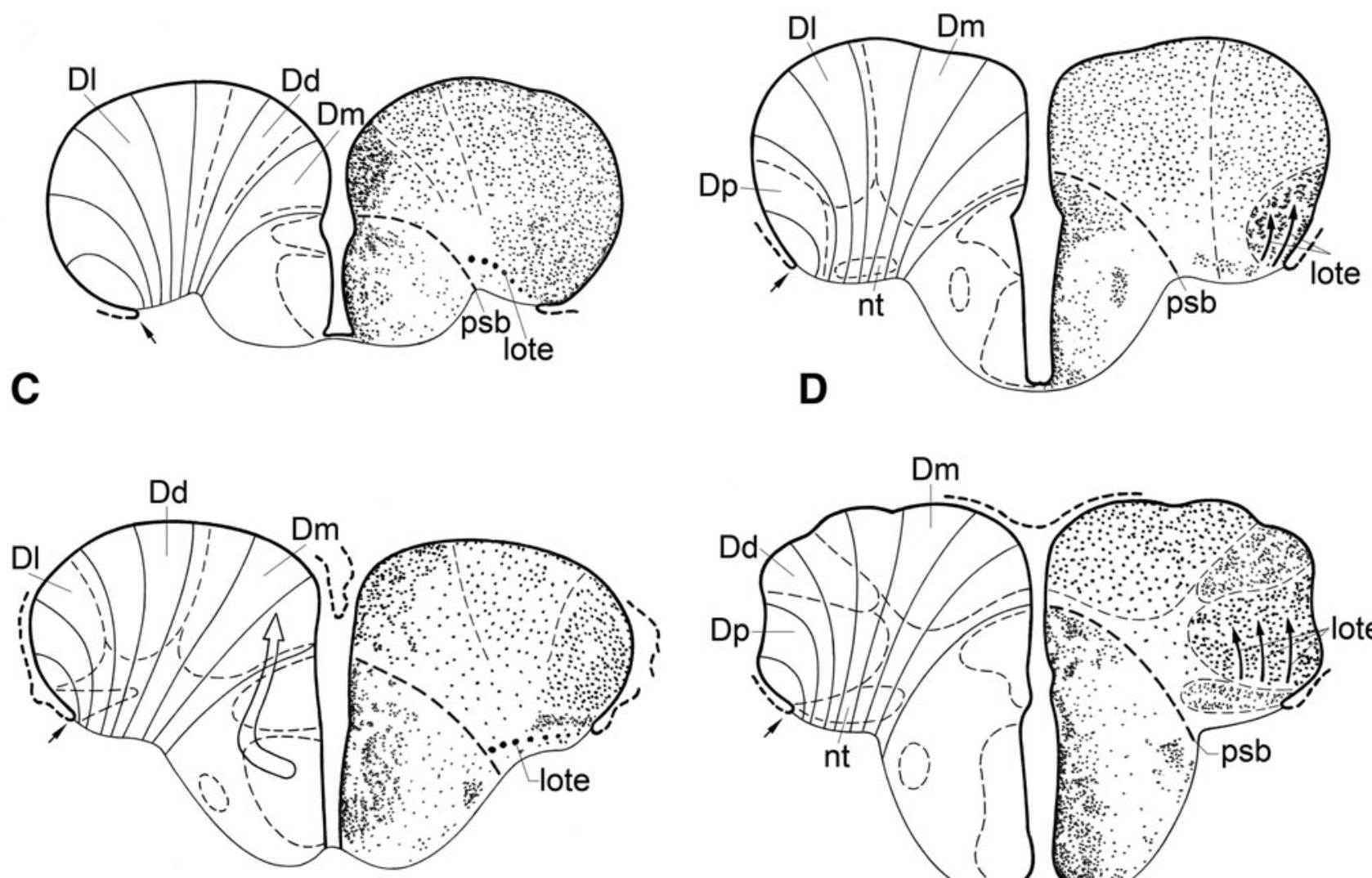

E
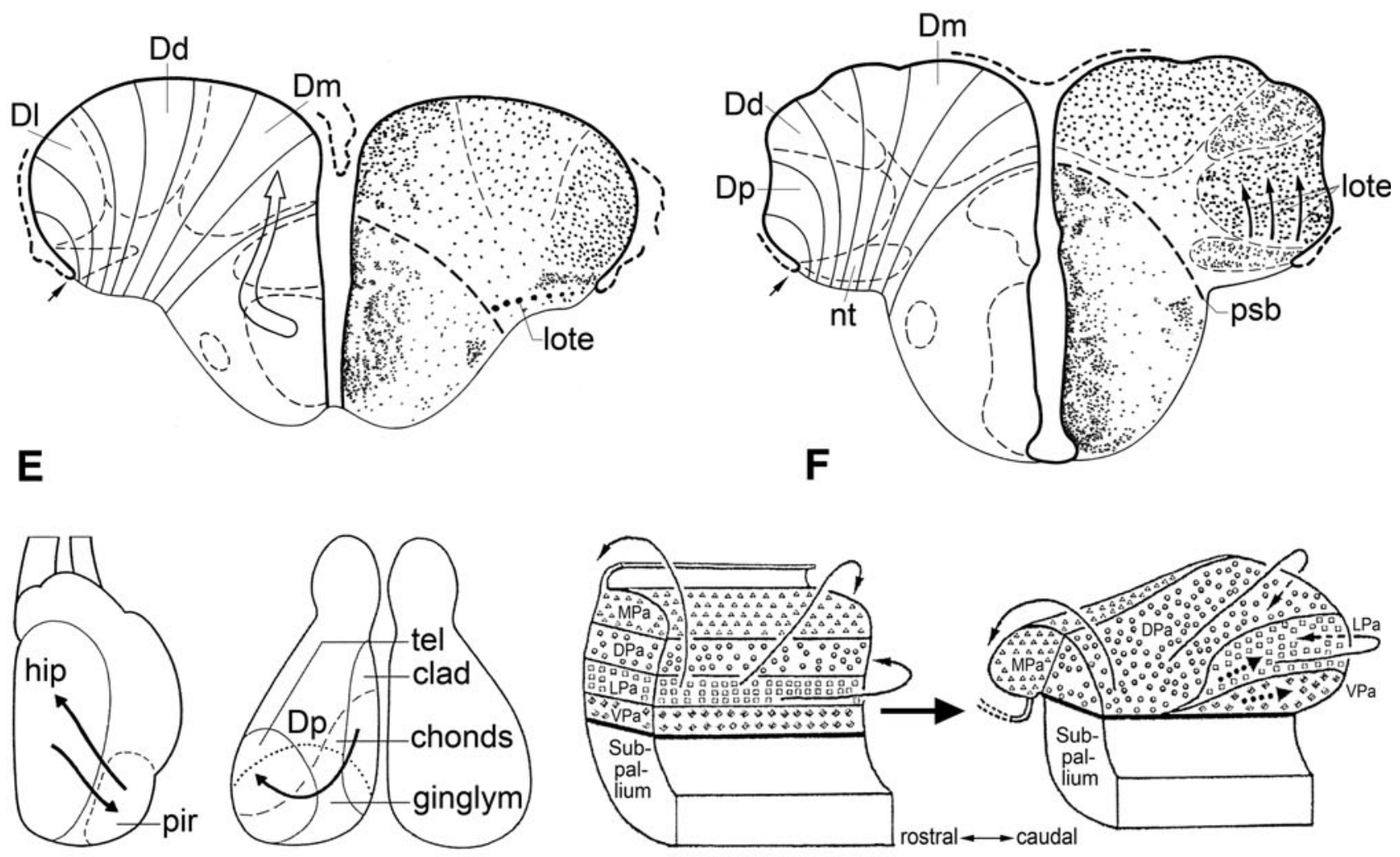

G

H

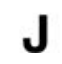

K 
Recent studies, based on the expression patterns of a large number of developmental regulatory genes, the immunohistochemical localization of neurotransmitters and related molecules, and the presence of modulatory neuroactive substances, have shown that in the pallium of all tetrapod groups, four longitudinal zones can be distinguished: the ventral pallium (VP), lateral pallium (LP), dorsal pallium (DP), and medial pallium (Puelles 2001; Brox et al. 2003, 2004; Moreno et al. 2008). It should be emphasized that these zones represent radially arranged histogenetic units, extending from the ventricular surface to the meningeal surface. In amphibians, the neuronal perikarya within the histogenetic territories VP, LP, and DP are concentrated in a periventricular zone; only in $\mathrm{MP}$, i.e. the compartment giving rise to the hippocampal pallium, are the cells dispersed over almost the entire width of the wall (Fig. 7a). The various histogenetic processes (proliferation, migration of postmitotic cells and nuclear or laminar differentiation) occur essentially within the confines of the radial units. The postmitotic cells migrate outward, guided by the radial glial fibres. This radial migration is to be considered as the principal mode of neuronal migration within the various pallial components and within the central nervous system of vertebrates in general (Nieuwenhuys 1998b; Marín and López-Bendito 2007). However, it has been observed that in most parts of the neuraxis, including the telencephalon, contingents of cells may leave the radial units within which they were produced to reach their ultimate position after a shorter or longer tangential migration. Thus, neuroblasts in the embryonic telencephalon of mammals, stemming mainly from the subpallial medial ganglionic eminence, invade the pallium via a tangential migration (Fig. 6b). These cells contribute substantially to the formation of the cerebral cortex, where they differentiate into GABAergic interneurons. Evidence published during the last decade indicates that similar tangential migrations occur in the telencephalon of non-mammalian vertebrates, including amphibians (Moreno et al. 2008; Fig. 7a).

Turning now to the actinopterygians, it should be mentioned first of all that detailed gene expression studies, aimed at locating the homologues of the tetrapod pallial zones VP, LP, DP, and MP, have not been carried out as yet. However, in light of the evidence from tetrapods, the following five assumptions seem to be justified:

1. Because in the pallium of tetrapods a number of longitudinally arranged zones can be distinguished, it may be expected that the actinopterygian pallium is likewise subdivisible into a number of longitudinal zones. However, due to the eversion, these zones will show a reversal of medial-to-lateral topography with respect to those in the evaginated and inverted pallium of tetrapods.

2. Because in the pallium of all tetrapods, the fundamental histogenetic units stretch from the ventricular to the meningeal surface, it may be assumed that their homologues in the actinopterygian pallium do the same.

3. Because in the pallium of the evaginated forebrains of tetrapods, the boundaries of the individual histogenetic units diverge from the smaller ventricular surface to the larger meningeal surface (Fig. 7a); it may be assumed that in the everted actinopterygian pallium these boundaries converge from the larger ventricular surface to the smaller meningeal surface and in general follow the pattern of the radial curves or vectors, discussed in the first part of this paper.

4. Because in the pallium of tetrapods, and indeed throughout the vertebrate neuraxis, most neuroblasts, migrate outward from their respective periventricular germinal zones, guided by radial glial fibres, it may be assumed that such radial migrations also prevail in the forebrain of actinopterygians.

5. Because it has been observed that in the telencephalon of tetrapods, and of lampreys and sharks as well (cf. Nieuwenhuys 2009c), neuroblasts migrate tangentially from the subpallium towards the pallium, it may be expected that a corresponding migration also occurs in actinopterygians.

The data available do not render it possible to check the correctness of all of these assumptions. However, the narrow periventricular cell layer in the pallium of cladistians is, according to Northcutt and Braford (1980) and Holmes and Northcutt (2003), subdivisible into four longitudinal zones, designated by them as P1v, P1d, P2, and P3 (Fig. 7b). Considering similarity in primary topological position as the principal criterion for establishing the homology of cell masses (cf. Nieuwenhuys 2009a), I homologize the cladistian zones P1v, P1d, P2, and P3, with the tetrapod pallial fields VP, LP, DP, and MP, respectively (Fig. 7a). As a matter of course, it remains desirable to substantiate these homologies with gene expression studies.

In the pallium of all other actinopterygian groups, the neuronal perikarya are dispersed throughout the entire width of the thickened wall, and there is a clear tendency towards the formation of separate cell masses. Within the area dorsalis (D) of most teleosts (exemplified here by the three-spined stickleback, Gasteosteus aculeatus: Fig. 7c, d and the zebrafish, Danio rerio: Fig. 7e, f), separate medial (Dm), dorsal (Dd), and lateral (Dl) areas can be distinguished along its greatly extended ventricular surface. Area Dm can also be distinguished in chondrosteans, 
ginglymodes, and halecomorphs (Fig. 1h, 1, p), but no distinct cytoarchitectonic differences can be observed in the remaining parts of $\mathrm{D}$. Accordingly, the region situated lateral to Dm has been designated $\mathrm{Dd}+1$ in these three groups. In teleosts, the caudolateral part of D contains a periventricular area, composed of closely packed cells, which are often arranged in a number of irregular layers. This area represents in my opinion a specialized posterior part of Dl, the reason why I designated it in my earlier work (Nieuwenhuys 1963) as Dlp. However, because most recent authors consider this area as a separate posterior portion of D, it is currently generally labelled as Dp (Figs. 5e, f, 7d, f). It has already been mentioned that the area dorsalis of osteoglossomorph teleosts is highly differentiated. In this group, the areas Dm and Dd form sharply defined laminated structures, while Dl is divided into three subareas, Dla, Dlb, and Dlc (Nieuwenhuys 1962b; Fig. 6a).

Reference to Figs. 1h, 1, p, 6a and 7c-e, shows clearly that the boundaries of the various cell masses, delineated in the area dorsalis or pallium of chondrosteans, ginglymodes, halecomorphs, and teleosts, converge from the larger ventricular surface to the smaller meningeal surface and closely adhere to the direction of the radial vectors. The reason that this correspondence is not clear in the section through the forebrain of the zebrafish shown in Fig. 7f may well be that at this level the caudally directed eversion prevails over the lateral eversion.

Direct evidence concerning the mode of migration of neuroblasts in the pallium of actinopterygian fishes is lacking. However, it seems plausible that most of the neurons that populate the various cytoarchitectural units have migrated radially inward from their respective ventricular germinal zones. As regards subpallial-pallial migration, it is important to note that Mueller and Wullimann (2009) have recently observed such a tangential migratory stream in larval zebrafishes (Fig. 7e).

It may be concluded that the cell masses delineated represent fundamental radial units, directly comparable to those in the pallium of tetrapods. Butler (2000) and Nieuwenhuys (2009a), assuming that a simple eversion is the principal morphogenetic event in the forebrain of actinopterygians, have accordingly homologized the mediolaterally arranged cell masses $\mathrm{Dm}, \mathrm{Dd}$, and $\mathrm{Dl}+\mathrm{Dp}$, on topological grounds with the cell zones VP + LP, DP, and MP, respectively, in the pallium of tetrapods. The interpretations of the actinopterygian forebrain presented long ago by Holmgren $(1920,1922)$ and Kuhlenbeck (1929) were based on the same principle.

The sole and single reason why several authors have rejected the concept of a simple eversion is that in teleosts, cell group $\mathrm{Dp}$, which is typically situated close to the taenia (Fig. 7d, f), is the pallial target of massive projections from the olfactory bulb, whereas in amphibians, and in all other gnathostomes with evaginated forebrains, the principal olfactory recipient zone, i.e. VP $+\mathrm{LP}$, is located far from this landmark (Fig. 7a). As will appear from the following survey, all of these authors have sought to explain this remarkable discrepancy by postulating extensive shifts of one or more cell groups in the pallium of actinopterygian fishes.

Sheldon (1912) compared the structural relations found in the telencephalon of the carp Cyprinus carpio directly with those in mammals. He noted that in the latter group a conspicuous lateral olfactory tract arches over an external groove, the sulcus rhinalis, and terminates in a caudolateral protuberance, known as the pyriform lobe. On the basis of topographical correspondence, he interpreted the sulcus externus in the carp as sulcus rhinalis, and the cell mass, denoted here as Dp, as nucleus pyriformis (Fig. 8b). Moreover, he interpreted the cell mass, termed here Dm, as a primordium of the mammalian hippocampus. Sheldon knew, however, that the teleostean forebrain walls bend outward during development, and he understood that if this eversion would be the whole story, the process would lead to a mediolateral reversal of the cell masses in the teleostean pallium, relative to their orientation in evaginated forebrains, which would be incompatible with his interpretation. Sheldon solved this problem by assuming that during development, a plastic rearrangement of cell groups occurs in teleostean forebrains, such that a population of cells, initially situated close to the taenia, gradually changes place with a more medial population (Fig. $7 \mathrm{~g}$ ). Johnston (1912, p. 434) criticized this 'transposition hypothesis', by stating "No facts are given upon which this hypothesis of a modified eversion is based and the author [i.e. Johnston, R. N.] has seen nothing in his study of larval stages of ganoids and teleosts to give support to it". Källén (1951) likewise concluded that there is no embryological evidence supporting Sheldon's hypothesis.

Northcutt and Braford (1980) (see also Northcutt and Davis 1983; Northcutt 2001) studied the cell masses and the distribution of the secondary olfactory projections in the telencephalon of five actinopterygian species, the cladistian Polypterus, the chondrostean Scaphirhynchus, the ginglymode Lepisosteus, and two teleosts, Salmo and Lepomis. They found that the pallial terminal fields of the secondary olfactory projections differed in that they occupied a medial position in Polypterus, a caudomedial position in Scaphirhynchus, a caudal position in Lepisosteus, and a caudolateral position in Salmo and Lepomis (Fig. 7h). Northcutt and Braford also reported that in all species examined the pallial olfactory terminal field matches exactly with a particular cell mass or field. In Polypterus, this terminal field corresponded with the area designated by these authors as P1 (Fig. 7b); in the teleosts examined it matched with Dp (Fig. 7d, f), and in 


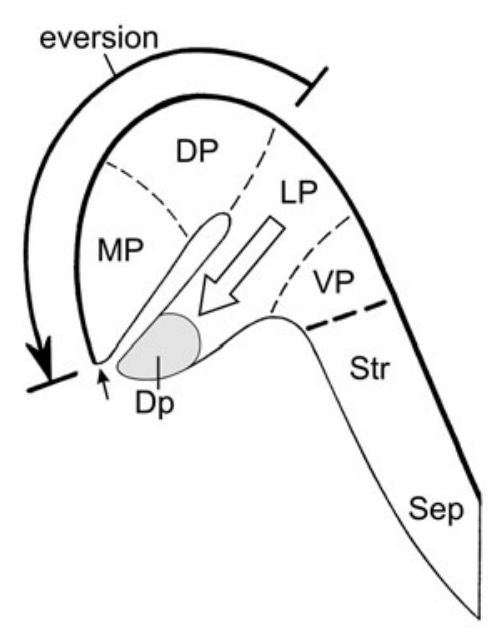

A

Fig. 8 The development and location of cell mass $\mathrm{Dp}$ in the forebrains of teleosts. a According to the partial pallial eversion hypothesis of Wullimann and Mueller, the teleostean homologues of the tetrapod cell zones LP and VP (cf. Fig. 7a) do not participate in the eversion. Neuroblasts, originating from the medially situated ventricular matrix of LP, are supposed to migrate laterally and to form the submeningeal cell mass DP, located directly ventral to the taenia

Scaphirhynchus and Lepisosteus the olfactory parts of the pallium were likewise labelled as Dp.

In light of the observations just summarized, Northcutt and Braford advanced a new hypothesis which they called the 'eversion-rearrangement theory'. This theory includes the following corollaries: (1) The primitive position of Dp was initially medial, just like that of P1 in Polypterus. (2) During phylogeny, Dp has migrated caudally and laterally to attain a caudolateral position in the teleostean pallium (Fig. 7h). (3) The lateral (plus ventral) pallium of amphibians and other tetrapods (Fig. 7a) is to be regarded on positional and connectional grounds as homologous to area P1 in cladistians, and based on the same grounds, both are believed to be homologous to Dp in chondrosteans, ginglymodes, and teleosts. The name 'eversion-rearrangement theory' was chosen, because the shifts in position of Dp were considered incompatible with a simple eversion. The proposed migration of cell mass Dp will be discussed below; here I confine myself to the following remarks. (1) There can be no doubt that area P1 of cladistians is homologous with the lateral (plus ventral) pallial fields of amphibians and other tetrapods. (2) As detailed in a previous study (Nieuwenhuys 2009a), the lateral olfactory tract of amphibians and other tetrapods (Fig. 7a, loti) is homologous with the medial olfactory tract of cladistians (Fig. 7b, mot) and not with the small but distinct lateral olfactory tract of this group (Holmes and Northcutt 2003; Fig. $7 \mathrm{~b}$, lote). Because the cladistian lote has an obvious homologue in all actinopterygian groups, including teleosts and to the everted homologue of the tetrapod cell zone MP. b Transverse section through the caudal part of the telencephalon of the carp Cyprinus carpio, reproduced from Sheldon (1912). It is clear that, according to that author, cell mass Dp (his nucleus pyriformis) occupies a periventricular position and is located dorsal to the taenia

(Fig. 7c, e), the area of termination of the teleostean lote, i.e. cell mass Dp (Fig. 7d, f) cannot be homologized on connectional grounds with the cladistian area P1 (Fig. 7b) or the amphibian pallial fields VP + LP (Fig. 7a). (3) I remained unable to delineate in the pallium of chondrosteans and ginglymodes a cytoarchitectonic entity, corresponding to the cell mass, which Northcutt and Braford designated as $\mathrm{Dp}$ in these groups.

Another 'new eversion model' was recently proposed by Yamamoto et al. (2007). It is based on experimental hodological data and on an analysis of the organization of the pallium in mature specimens of a cyprinid teleost, the common goldfish. The authors start with the simple preeverted condition of the forebrain, in which the pallium is postulated to be composed of four, dorsoventrally arranged columns: MPa, DPa, LPa, and VPa (Fig. 7j). In order to explain the positions of $\mathrm{Dp}$ and of the nucleus taeniae, i.e. another cell mass in the caudolateral part of the pallium, which as its name indicates, abuts on the taenia, they hypothesized that, during development, the periventricular parts of LPa and VPa shift caudally away from the other zones and are lost at rostral levels, where their vestiges will produce few or no neurons (Fig. 7k). Because the eversion occurs not only in a lateral direction but also in a caudal direction, the columns $\mathrm{LPa}$ and VPa ultimately reach a caudolateral position where they give rise to $\mathrm{Dp}$ and the nucleus taeniae, respectively.

The 'modified eversion theories' of Sheldon (1912), Northcutt and Braford (1980), and Yamamoto et al. (2007), 
just discussed, have in common that they all postulate a tangential shift of one or more pallial cell masses. Tangential migrations are very common, and it has already been mentioned that in the telencephalon of many vertebrate groups, including teleosts, cells migrate massively from the subpallium to the pallium where they are integrated as GABAergic interneurons into networks of glutamatergic projection neurons (Marín and López-Bendito 2007). To give another example, neuroblasts, originating from the most dorsal part of the rhombencephalic alar plate, migrate tangentially in compact streams to the medial part of the basal plate, where they give rise to the inferior olive and, in mammals, to the pontine nuclei. It should be emphasized that the tangential migrations proposed by the three (groups of) authors mentioned above are of a totally different nature. In these cases, periventricular cell masses are supposed to migrate tangentially, directly along the ventricular surface. To the author's knowledge, embryological evidence for the existence of such subventricular migrations is entirely lacking. Moreover, this mode of migration implies that the cell masses in question change their primary topological relations in the course of ontogeny (Sheldon 1912; Yamamoto et al. 2007) or phylogeny (Northcutt and Braford 1980). The present author strongly believes that these relations are conservative among actinopterygians and among vertebrates in general. Fundamental morphological units, such as the pallial areas VP, LP, DP, and MP, are known to maintain their mutual topological relations throughout all tetrapod groups, and there is no reason to assume that they will do otherwise in actinopterygians.

The fourth and final concept of the organization of the pallium of teleosts to be discussed here is the 'partial eversion hypothesis', enunciated by Wullimann and Mueller (2004) and elaborated by Mueller and Wullimann (2009), and Wullimann (2009), who studied larval and adult specimens of the zebrafish Danio rerio, a cyprinid teleost. These authors argued that in teleostean forebrains, a simple and complete eversion, with its consequent reversal of pallial fields, is not compatible with the location of the principal olfactory input to the pallium. To reconcile this paradox, they surmised that in the teleostean pallium eversion is confined to the homologues of the tetrapod medial and dorsal pallial fields, MP and DP, but that the homologue of the (olfactory) lateral pallium, LP, does not participate in eversion (Fig. 8a, large, curved arrow). Neuroblasts, originating from the ventricular matrix of the medially situated, uneverted LP homologue, were supposed to migrate laterally, and give rise to the submeningeally situated cell mass Dp, located directly ventral to the homologue of MP (Fig. 8a, open arrow). Wullimann and Mueller remained unable to locate the attachment of the telencephalic tela in their histological material, yet they supposed that this landmark is situated between the ventral margin of the MP homologue, and the dorsal margin of Dp (Fig. 8a, small arrow). As discussed in the first section of the present paper, in adult teleosts, the compact telencephalic periventricular cell zone may retain the proliferative capacity of a true matrix. Wullimann (2009) and Mueller and Wullimann (2009) claimed that the experiments of Lillesaar et al. (2009), in which adult zebrafish were incubated with the thymidine analogue BrdU, have clearly shown that the cell mass Dp is, in contrast to the remaining pallium, not covered by a ventricular proliferative zone and therefore does not seem to be everted.

In the present paper, the location of the attachment of the choroid roof in the forebrain of the zebrafish has been demonstrated for the first time. It is clear that this landmark is located ventrally to $\mathrm{Dp}$ and hence that the lateral surface of this cell mass is ventricular rather than meningeal (Figs. 5e, f, 7f). This result is in harmony with findings in other cyprinids, as well as with data available on the telencephalon of the zebrafish itself. As regards other cyprinids, Sheldon (1912) established that in the carp Cyprinus carpio, Dp, i.e. the cell mass denoted by him as the nucleus pyriformis, is a periventricular structure, situated dorsal to the taenia (Fig. 8b); Northcutt $(2006,2008)$ and Yamamoto et al. (2007), who studied the telencephalon of the goldfish Carassius auratus, arrived at a similar conclusion. As regards data on the zebrafish itself, it has already been mentioned that in the rostral and intermediate parts of the telencephalon of all teleosts, the lateral part of the lateral olfactory tract (lote) abuts precisely on the taenia (Figs. 3, $5 \mathrm{~h}-\mathrm{k}, 7 \mathrm{c}, \mathrm{e})$, and that the lateral part of the nucleus taeniae does exactly the same in the caudal part of the teleostean forebrain (Figs. 5f, 7e, f, 8b). In the zebrafish brain atlas of Wullimann et al. (1996) the taenia is absent. However, if we use the positions of the lote and the nucleus taeniae to establish the location of this landmark, it is again immediately clear that the free lateral surface of the cell mass labelled in this atlas as Dp is ventricular.

Finally, comparison of the transverse section through the forebrain of the zebrafish, shown in Fig. $7 d$ in the publication of Lillesaar et al. (2009), which was reproduced as Fig. 4d in Mueller and Wullimann (2009), with our own material, revealed that the ventrolateral end of the proliferative pallial zone coincides with the taenia. However, the area labelled and delineated as Dp by the authors mentioned has nothing to do with that cell mass, but rather corresponds with the cell-poor zone lateral to the shallow sulcus externus. In order to make this clear, I transferred the delineation of Dp, as shown in Fig. $4 \mathrm{c}$ of Mueller and Wullimann (2009), to Fig. 5e in the present publication.

If we survey the various hypotheses on the organization of the pallium in actinopterygian fishes, discussed above, it must be concluded that Sheldon (1912), Northcutt and 
Braford (1980), and Yamamoto et al. (2007) postulated highly improbable tangential shifts of cell masses in their respective 'modified eversion' theories, for which ontogenetic evidence is lacking, and that the 'partial eversion' hypothesis of Wullimann (2009) and Mueller and Wullimann (2009) is entirely based on an erroneous localization of the taeniae, i.e. the sites where the greatly expanded ventricular surfaces of the actinopterygian telencephalic hemispheres end, and their greatly reduced meningeal surfaces begin. There are as yet no reasons whatsoever to doubt that the pallium of actinopterygian fishes is the product of a simple and complete eversion. It has already been mentioned that studies of the expression patterns of developmental regulatory genes have shown that the pallium in tetrapods develops from four longitudinally arranged radial units. It will be of great comparative interest to establish whether these basic pallial zones are also present in actinopterygians and, if so, to analyse their development in each of the five actinopterygian clades.

Acknowledgments I thank Dr. Lawrie Bannister for valuable comments on an earlier version of this article, Joop van Heerikhuize for preparing the photomicrographs, Wil Maas and Ton Put for help with the illustrations, Dr. Paula van Tijn for making available the histological series of the zebrafish brains, Dr. Jenneke Kruisbrink for literature retrieval, and Suzanne Bakker MSc for moral support and reference management.

Open Access This article is distributed under the terms of the Creative Commons Attribution Noncommercial License which permits any noncommercial use, distribution, and reproduction in any medium, provided the original author(s) and source are credited.

\section{References}

Ampatzis K, Dermon CR (2010) Regional distribution and cellular localization of $\beta_{2}$-adrenoceptors in the adult zebrafish brain (Danio rerio). J Comp Neurol 518:1418-1441

Bannister LH (1973) Forebrain structure in Phoxinus phoxinus, a teleost of the cyprinid family. J Hirnforsch 14:413-433

Braford MR Jr (1995) Comparative aspects of forebrain organization in the ray-finned fishes: touchstones or not? Brain Behav Evol 46:259-274

Braford MR Jr (2009) Stalking the everted telencephalon: comparisons of forebrain organization in basal ray-finned fishes and teleosts. Brain Behav Evol 74:56-76

Brox A, Puelles L, Ferreiro B, Medina L (2003) Expression of the genes GAD67 and Distal-less-4 in the forebrain of Xenopus laevis confirms a common pattern in tetrapods. J Comp Neurol 461:370-393

Brox A, Puelles L, Ferreiro B, Medina L (2004) Expression of the genes Emx1, Tbr1, and Eomes (Tbr2) in the telencephalon of Xenopus laevis confirms the existence of a ventral pallial division in all tetrapods. J Comp Neurol 474:562-577

Butler AB (2000) Topography and topology of the teleost telencephalon: a paradox resolved. Neurosci Lett 293:95-98

Crosby EC, DeJonge BR, Schneider RC (1966) Evidence for some of the trends in the phylogenetic development of the vertebrate telencephalon. In: Hassler R, Stephan H (eds) Evolution of the forebrain. Plenum Press, New York, pp 117-135

Droogleever Fortuyn J (1961) Topographical relations in the telencephalon of the sunfish, Eupomotis gibbosus. J Comp Neurol 116:249-264

Forlano PM, Deitcher DL, Myers DA, Bass AH (2001) Anatomical distribution and cellular basis for high levels of aromatase activity in the brain of teleost fish: aromatase enzyme and mRNA expression identify glia as source. J Neurosci 21:8943

Friedrich RW, Jacobson GA, Zhu P (2010) Circuit neuroscience in zebrafish. Curr Biol 20:R371-R381

Gage SP (1893) The brain of Diemyctilis viridescens from larval to adult life and comparison with the brain of Amia and of Petromyzon. The Wilder Quarter-Century Book. Comstock Publishing Company, Ithaca, pp 259-313

Herrick CL (1891) Studies on the brains of some American freshwater fishes. Continued. J Comp Neurol 1:333-358

Holmes PH, Northcutt RG (2003) Connections of the pallial telencephalon in the Senegal bichir, Polypterus. Brain Behav Evol 61:113-147

Holmgren N (1920) Zur Anatomie und Histologie des Vorder- und Zwischenhirns der Knochenfische. Acta Zool 1:137-315

Holmgren N (1922) Points of view concerning forebrain morphology in lower vertebrates. J Comp Neurol 34:491-459

Johnston JB (1911) The telencephalon of ganoids and teleosts. J Comp Neurol 21:489-591

Johnston JB (1912) On the teleostean forebrain. Anat Rec 6:423-438

Källén B (1950) A contribution to the ontogenetic development of the nuclei in the forebrain in Lepisosteus. Acta Anat 9:297-308

Källén B (1951) Some remarks on the ontogeny of the telencephalon in some lower vertebrates. Acta Anat 11:537-548

Kálmán M (1998) Astroglial architecture of the carp (Cyprinus carpio) brain as revealed by immunohistochemical staining against glial fibrillary acidic protein (GFAP). Anat Embryol 198:409-433

Kastenhuber E, Kratochwil CF, Ryu S, Schweitzer J, Driever W (2010) Genetic dissection of dopaminergic and noradrenergic contributions to catecholaminergic tracts in early larval zebrafish. J Comp Neurol 518:439-458

Kirsche W (1967) Über postembryonale Matrixzonen im Gehirn verschiedener Vertebraten und deren Beziehung zur Hirnbauplanlehre. Z Mikrosk Anat Forsch 77:313-406

Kuhlenbeck H (1929) Die Grundbestandteile des Endhirns im lichte der Bauplanlehre. Anat Anz 67:1-51

Lillesaar C, Stigloher C, Tannhäuser B, Wullimann MF, Bally-Cuif L (2009) Axonal projections originating from raphe serotonergic neurons in the developing and adult zebrafish, Danio rerio, using transgenics to visualize raphe-specific pet1 expression. J Comp Neurol 512:158-182

Marín O, López-Bendito G (2007) Neuronal migration. In: Kaas JH (ed) Evolution of nervous systems, vol 1. Elsevier, Amsterdam, pp 169-186

Meader RG (1939) The forebrain of bony fishes. Proc Kon Ned Akad Wetensch Sect Sci 42:657-670

Moreno N, González A, Rétaux S (2008) Evidences for tangential migrations in Хenopus telencephalon: developmental patterns and cell tracking experiments. Dev Neurobiol 68:504-520

Mueller T, Wullimann MF (2009) An evolutionary interpretation of teleostean forebrain anatomy. Brain Behav Evol 74:30-42

Mueller T, Vernier P, Wullimann MF (2004) The adult central nervous cholinergic system of a neurogenetic model animal, the zebrafish Danio rerio. Brain Res 1011:156-169

Nieuwenhuys R (1960) Het telencephalon derActinopterygii. PhD thesis, University of Amsterdam, Amsterdam, p 128

Nieuwenhuys R (1962a) The morphogenesis and the general structure of the actinopterygian forebrain. Acta Morphol Neerl Scand 5:65-78 
Nieuwenhuys R (1962b) Trends in the evolution of the actinopterygian forebrain. J Morphol 111:69-88

Nieuwenhuys R (1963) The comparative anatomy of the actinopterygian forebrain. J Hirnforsch 13:171-192

Nieuwenhuys R (1964) Further studies on the general structure of the actinopterygian forebrain. Acta Morphol Neerl Scand 6:65-79

Nieuwenhuys R (1998a) Comparative neuroanatomy: place, principles and programme. In: Nieuwenhuys R, ten Donkelaar HJ, Nicholson C (eds) The central nervous system of vertebrates, vol 1. Springer, Berlin, pp 273-326

Nieuwenhuys R (1998b) Histogenesis. In: Nieuwenhuys R, Ten Donkelaar HJ, Nicholson C (eds) The central nervous system of vertebrates, vol 1. Springer, Berlin, pp 229-272

Nieuwenhuys R (2009a) The forebrain of actinopterygians revisited. Brain Behav Evol 73:229-252

Nieuwenhuys R (2009b) On old and new comparative neurological sinners: the evolutionary importance of the membranous parts of the actinopterygian forebrain and their sites of attachment. J Comp Neurol 516:87-93

Nieuwenhuys R (2009c) The structural organization of the forebrain: a commentary on the papers presented at the 20th Annual Karger Workshop 'Forebrain evolution in fishes'. Brain Behav Evol 74:77-85

Nieuwenhuys R (2009d) Analysis of the structure of the brain stem of mammals by means of a modified D'Arcy Thompson procedure. Brain Struct Funct 214:79-85

Nieuwenhuys R, Bauchot R, Arnoult J (1969) Le développement du télencéphale d'un poisson osseux primitif, Polypterus senegalus Cuvier. Acta Zool 50:101-125

Northcutt RG (2001) The telencephalon of ray-finned fishes revisited. Brain Behav Evol 57:230

Northcutt RG (2006) Connections of the lateral and medial divisions of the goldfish telencephalic pallium. J Comp Neurol 494:903-943

Northcutt RG (2008) Forebrain evolution in bony fishes. Brain Res Bull 75:191-205

Northcutt RG, Braford MR Jr (1980) New observation on the organization and evolution of the telencephalon of the actinopterygian fishes. In: Ebbeson SOE (ed) Comparative neurology of the telencephalon. Plenum Press, New York, pp 41-98

Northcutt RG, Davis RE (1983) Telencephalic organization in rayfinned fishes. In: Davis RE, Nortcutt RG (eds) Fish Neurobiology, vol 2. University of Michigan Press, Ann Arbor, pp 203-236

Puelles L (2001) Brain segmentation and forebrain development in amniotes. Brain Res Bull 55:695-710

Schnitzlein HN (1968) Introductory remarks on the telencephalon of fish. In: Ingle D (ed) The central nervous system and fish behavior. University of Chicago Press, Chicago, pp 97-100

Segaar J (1965) Behavioural aspects of degeneration and regeneration in fish brain: a comparison with higher vertebrates. Progr Brain Res 14:143-231

Sheldon RE (1912) The olfactory tracts and centers in teleosts. J Comp Neurol 22:177-339

Studnička FK (1896) Beiträge zur Anatomie und Entwicklungsgeschichte des Vorderhirns der Cranioten. Sitzungsber K Böhm Ges Wiss Math Nat Kl 15:1-32

Vázquez M, Rodríguez F, Domezain A, Salas C (2002) Development of the brain of the sturgeon Acipenser naccarii. J Appl Ichthyol $18: 275-279$

Wullimann MF (2009) Secondary neurogenesis and telencephalic organization in zebrafish and mice: a brief review. Integr Zool 4:123-133

Wullimann MF, Mueller T (2004) Teleostean and mammalian forebrains contrasted: evidence from genes to behavior. J Comp Neurol 475:143-162

Wullimann MF, Rink E (2002) The teleostean forebrain: a comparative and developmental view based on early proliferation, Pax6 activity and catecholaminergic organization. Brain Res Bull 57:363-370

Wullimann MF, Rupp B, Reichert H (1996) Neuroanatomy of the zebrafish brain: a topological atlas. Birkhäuser, Basel

Yamamoto N, Ishikawa Y, Yoshimoto M, Xue HG, Bahaxar N, Sawai $\mathrm{N}$, Yang CY, Ozawa H, Ito H (2007) A new interpretation on the homology of the teleostean telencephalon based on hodology and a new eversion model. Brain Behav Evol 69:96-104 